\title{
The Model Concepts of the Human Perception Mechanism
}

\author{
Vladimir Vasilevich Brutov ${ }^{1}$ \\ ${ }^{1}$ Sholokhov Moscow State University for the Humanities, Moscow, Russian Federation \\ Correspondence: Vladimir Vasilevich Brutov, Sholokhov Moscow State University for the Humanities, 16-18, \\ Verkhnyaya Radishchevskaya street, Moscow 109240, Russian Federation. E-mail: agraml@mail.ru
}

\author{
Received: October 11, 2014 Accepted: November 16, 2014 Online Published: February 25, 2015 \\ doi:10.5539/ass.v11n6p127 URL: http://dx.doi.org/10.5539/ass.v11n6p127
}

\begin{abstract}
The paper shows the analogy between the natural mechanisms of perception and the modeling methods created by the man himself. The paper also shows the mechanism of the mental models' formation in human consciousness in a process of the reality perception. There was made an assessment of the limitations which are peculiar to these models, leading to a significant mismatch of the mental models to the real objects and to phenomena of the world as well. There were found the main factors which are the reasons of the mental models non-compliance and the reality itself.
\end{abstract}

Keywords: model, a model perception, an ideal model, a mental model, an intellectual model, a visual code, a model field of consciousness, an interpretive algorithm, a worldview, the egocentrism

\section{Introduction}

At the present stage of the modern methods development of understanding of the world is becoming clearer that the natural mechanisms of human perception is largely similar to the artificial methods of modeling, that entered the arsenal of modern science firmly. Indeed, the recognition of a modeling structure of the perception process, leads to the necessity to recognize significant differences between the current reality and the human model representations about it.

Because differences between a model and a described phenomenon always exist, and it is an inevitable consequence of the modeling methods (Bender, 1978; Gershenfeld, 1999). Just recently, the majority of people believed in the uniqueness and adequateness of their reality perception, because the concept of a modal nature of a perception was alien to the great masses of people. However, in a modern society, statements about the model character of perception do not evoke the same opposition as it was before. As an example, it may be noted that such a public resource like Wikipedia says that thinking acquires unlimited possibilities of a speculative and model vision of the world (Thinking. In Wikipedia, 2014). The wide acceptance of the model structure idea and conventions of our perception and thinking, in our opinion, become quite relevant now, and it is another step on the ladder of the evolution of the human species.

\section{Method}

Consider the review, comparison and analysis of the researches on the problem. At the present stage of the scientific concepts' development it becomes clear, that in a perception process, a human brain, firstly, takes a lot of sensory data from the body receptors, and secondly, processes them through existing in his arsenal interpretive algorithms, thirdly, builds a mental model of a surrounding reality, which is grouped from the models of individual objects and phenomena. Actually, this is a three-stage scheme of a human perception.

To the attempts to simulate such data processing algorithms in a human brain a special area of modern psychology is devoted. This area is devoted to modeling the processes of the human mind by artificial intelligence. A cognitive psychology deals with such problems considering. One of its representatives Magazov $\mathrm{S}$. argues that the basic foundation of the cognitive researches is that there are always two realities against an individual: the mental and the "real" (objective) .The "objective" reality is given to a man through the senses. It does not change during a cognitive process.

Mental model is constructed by the individual within a cognitive process which was given from the birth as a product of evolution. Mental model allows the individual to navigate in the "objective" reality and provides him a survival (Magasov, 2007). 
In a cognitive psychology, we introduce the concept of visual code as a fixed in the brain information processing algorithm coming from a receptor, it is assumed that the visual codes (images) "real" objects are kept in the mind as well as the codes (cognitive maps) of a complex structured physical world scenes . A visual object code contains information about its geometric characteristics, the quality, and detailed information about the possible actions. The code generation mechanisms are developed during the evolution and depend on the biological species of a perceiver and its genetically determined abilities (Magasov, 2007). This means that the visual code elements are different for various types of species, are different for members of the same species which are at different stages of evolution, as well as different in time for one particular person, because these codes are formed gradually. Consequently, there are always the fundamental differences between the mental model and the surrounding reality.

One of the classics of modern psychology H. Helmholtz also directly links the contents of a mental model with the peculiarities of the perceiving consciousness. According to his opinion, human concepts are such the images, the content of which essentially depend on the nature of the perceiving consciousness and determine its characteristics (Gelmgolts, 1975).

Other psychologists also put in doubt the objectivity of the mental model: "Until recently it was believed that through the perception and the associated processes, we obtain reliable information about the objectively existing reality. The achievements in physics, psychology and other sciences during the last century revealed a relativity of what was considered as inviolable" (A reality perception, 2014). There are many psychological experiments in which it is recorded very clearly a distortion of reality perception (Brutov \& Rubleva, 2003).

If the researches in the psychology still remain on the surface of the problem, a modern engineering thought approached to the understanding of the nature of the perception modeling much closer. So Peter Senge in his book "The Fifth Discipline" introduces the concept of "an intellectual model." He states that the intellectual models-are the suppositions which are hidden deeply in the mind, generalizations or even pictures or images that influence human understanding of the world and a course of action chosen by people. Often people are not aware of the existence of these models and how they define the behavior of people (Senge, 2006). Peter Senge believes that people do not "own" their intellectual models. People are the intelligent models themselves. They are the tools by which people interact with the world. They are an inseparable part from the personal history of each individual and of his self-understanding and self-awareness (Senge, 2006).

Another representative of an engineering thought, M.S. Rubin, presented a whole system of the model thinking principles, consisting of 21 principles (Rubin, 2003).

MS Ruby comes to the necessity of postulating a mental space, in which the mental models exist and interact, thus, according to his words, the elements of a mental model, a mental model itself and their total, together with the estimates, form the mental space of interaction and conflict (Rubin, 2003). Such a mental space concept is similar to the concept of a "model of a field of consciousness" is an abstract space, which exists only in a imagination of an individual, in which consciously and unconsciously whole universe is constructed as well as the individual elements of nature (Brutov \& Rubleva, 2004).

In the analysis of the basics of human perception, inevitably comes the understanding, that as a result of this perception is the mental model of reality, this reality should be limited. Consequently, in the first place appears the question of the degree of our ideas' mismatch to the actually existing reality. To assess the degree of this non-compliance is advisable to recall the stages of the perception process, and try to analyze the simplification and limitations coming from this. First, the receptor base of the human body is very much limited; moreover, it is quite primitive in its structure. Receptors, which register the phenomena of the world is too small in relation to the entire spectrum of all possible external influences. Secondly, there is every reason to believe that in the brain activity while sensory data processing stage a huge amount of inconsistencies is introduced, which appear in the processes of simplification and schematization, which arise as a result an activity of mental algorithms' processing and interpretation of the sensory data. Visual codes, which according to what psychologists say, is a strictly fixed in a brain algorithms, designed to produce the perception results by means of the certain images and objects, clearly defined patterns of interactions of these objects. At the same time, any information which is not relevant to specific models of a human perception is distorted or ignored to provide the conservation of the everyday nature of a perception. Third, at the stage of the world picture constructing, in the resulting model should be introduce more distortions, which are defined by the social action patterns and stereotypes, imposed on a person in the process of socialization.

Thus, there is every reason to believe that the world is not what it is commonly believed. Unfortunately, an understanding of this fact is greatly complicated due to the fact that in the process of such an understanding the 
same interpretive algorithms of thinking are used, defects of which interferes an adequate worldview.

\section{Results}

The basis of a human perception is the unconscious simulation mechanisms, similar to those used by a person within a conscious modeling.

Mental models of man, both conscious and unconscious, have a number of significant limitations imposed by the principles of modeling. This leads to a significant non-compliance between these models and real objects and phenomena of the surrounding world.

The nature and adequacy of the human mental models of a reality are determined largely by the processes of socialization and education. Therefore, the most important task of a better society will be a need to surround the representatives of the younger generation of human society with the most developed system of the world perception and worldview.

One of the main factors which distort the reality when the mental models are constructed is a passion of a man, and first of all his egocentrism. Therefore, one of the most important tasks of the human evolution should be the release from passion, and primarily from egocentrism.

\section{Discussion}

To the understanding of the significant subjectivity of human perception some of the most visionary thinkers of our time come. So, LG Malinowski writes that in terms of information, in fact, it is always possible to point out an element of ignorance. This element can not be eliminated in the process of learning both, due to the limited perception of reality by the detalization ability and an ability to estimate time intervals. The recognition of this element, in fact, is an element of separation from reality in a perception from the knowledge of the cognitive subject. That is, a reality separation from knowledge about it (Malinovsky, 2003). Peter Senge in his book "The Fifth Discipline" approaches even more to understanding the subjectivity of a human perception stating that every manager knows that the best ideas often never reach an implementation stage. Because people are convinced more and more that a familiar situation" too early to celebrate" is not the cause of poor resolution, not a lack of will, and not even the lack of systematic thinking, but a certain intellectual model. More precisely, the new ideas do not reach the practical stage, because they conflict with deeply rooted world ideas, which mean that these phenomena do not allow people beyond the habitual ways of thinking and acting (Senge, 2006).

To the understanding of significant bias of our world perceptions, the famous American anthropologist Carlos Castaneda approached. He is convinced that the world is actually quite different than we imagine. There is something that affects the senses. This is a part that is real. An unreal part is what people senses say about this "something" (Castaneda, 1991).

As a result, analyzing the reasons of non-compliance of a human reality perception, it becomes clear that the main distortion of information is likely to occur at the receptors' data processing stage by the mental interpretive algorithms, very much limited by the social norms and the patterns of perception. Thinking about this, C. Castaneda states that while treating the results of a perception, people adjust them to a certain pattern. This pattern is a socially important part of a perception, which should be pointed out and isolated. Because it reduces the amount of a potentially possible perception (Castaneda, 1993). The socialization process is gradual. It occurs when a child grows up, who takes from the surrounding adults their perception model and behavior, copy them in his mind (Brutov, 2013). That is why the most important task of a developed society will appear an inevitable necessity to surround children with representatives of human society with the most perfect system of a world perception. Here is what C. Castaneda writes about this problem-Everyone who meets a child in his life, becomes teachers for him. They teach him to describe the world in a certain way, and in a certain moment a child begins to perceive the world in accordance with description, formed in his mind (Castaneda, 1972).

Let's try to find out what are the factors that cause such significant limitations of a human perception. It is impossible give an unambiguous answer to this question; however, there is every reason to believe that one of the major distorting factors is the human passion, his personal petty whimsicality. In this way you can define a passion as a tendency to follow his own personal psycho-physiological capriciously, which in this case, start to dominate the consciousness and subconsciously define all the behavior of this individual. Therefore, such a person turns into a weak creature, incapable of reasonable and strategic planning of his life, but, on the contrary, this person is always exposed by gusts of sensuality, being constantly in search of pleasures. In a support of this, some psychologists directly claim that mainly a tendency to a pleasure is a distorting factor underlying the formation of personal picture of the world: "In all of this, each of us feels the picture of the world as if it is personal. This is because the inner essence of a person is a desire to receive pleasure" (A reality perception, 
2014). C. Castaneda says that it is self-reflection and needs (Castaneda, 1991). A similar opinion is shared by all devotees of the Christian orthodoxy, who believe that the passion of a human isolates a man from the world and of his Creator, closing a man inside his own petty little world, which is not equal to an outside world, but also the opposite one, even hostile to it. Here is what St. Simeon the New Theologian writes about it (Alfeyev, 2000): "Now we are enslaved by so many passions, we are blinded and insensitive so that we don't even not know, to what depths of evils we fell into and don't not feel our poor state" (St. Symeon, 1993).

Most likely, the most significant of the passions by the negative impact on the adequacy of a human perception of the world is an egocentrism, which causes a person to turn in on himself and make himself "measure" of the world. Orthodox ascetics called egocentrism as the pride, the mother of all sins. C. Castaneda says that an egocentrism is a sense of self-importance, which, according to his words, is not something unpretentious and straightforward. On the one hand, is the core of all the best we have. And on the other-the entire inner core of humans' rot (Castaneda, 1991). All the objects and phenomena of the world in the mind of self-centered person are not "self-sufficient", and they are evaluated only from the perspective of consumption or exposure mainly on a person. His personal problems such person puts above the all. Thus, such a person ceases to be a harmonious element of the world; it becomes some kind of a semblance of a cancerous tumor on the body of the universe. The saddest thing is that an affected by egocentrism person is not aware of his unnatural state, but continues to believe that he was right about everything! C. Castaneda very hard in this phenomenon assessment: "I will tell you, we are strange animals. We are gone aside, but in our madness we assured ourselves that we understand everything correctly" (Castaneda, 1991). C. Castaneda believes that people fully captured by its private world view, and it makes them feel and act as if they know everything about the world (Castaneda, 1991). St. Symeon the New Theologian writes about that in a following way: "Passionate people think that all the other are passionate as well, and measure another man's foot by themselves" (St. Symeon, 1993). Apparently, the manifestations of passion take all internal human resources, needed to expand the capabilities of their perception that occur as a consequence of human evolution, corresponding to its true nature . But the human evolution requires all internal resources that are wasted by a passionate man, a simple indulgence to own personal weaknesses.

\section{Conclusion}

For a person, aspiring to growth and development, a necessary thing is a correct understanding of surrounding reality. Misconception of surrounding reality is often promoted by the lack of knowledge in a particular subject area and the lack of interdisciplinary connections. In our researches we use a research apparatus of cognitive psychology. It was determined that the mental model abilities' development of school-age children influence an increase and stability of natural sciences' knowledge. A continuation of these researches is a model perception abilities' development of students of various training areas. Development of model capabilities and correct visual codes of studied objects of junior students in a particular subject area will effectively develop professional competences of future specialists.

\section{References}

A reality perception. Retrieved January 27, 2014, from http://i-psy.ru/content/category/4/17/92/

Abdulgalimov, G. L. (2013). A New Model of Russian Professional Education. World Applied Sciences Journal, $27,826-829$.

Abdulgalimov, G. L. (2014). Progress of information society in Russia and deficit of staff potential. Life Science Journal, 8, 494-496.

Alfeyev, H. (2000). Saint Symeon, the New Theologian, and Orthodox Tradition (p. 352). Oxford University Press. http://dx.doi.org/10.1093/acprof:oso/9780198270096.001.0001

Bender, E. A. (1978). An Introduction to Mathematical Modeling (p. 256). New York: Dover.

Brutov, V. V. (2013). The problem of the educational work in high education institutions. Volgograd, Volgograd state pedagogical institution news, 5(80), 64-67.

Brutov, V. V., \& Rubleva, E. M. (2003). Psychological pedagogical suppositions of the model methods. The problems of the generalizations forming on the level of a physical worldview within the physics studying (pp. 188-190). General education institutions, pedagogical institute. Moscow: The publishing house MGOU.

Brutov, V. V., \& Rubleva, E. M. (2004). A physical worldview in a whole system of the worldviews. The problems of the generalizations forming on the level of a physical worldview within the physics studying. General educational institution, pedagogical institutions. In The reports of the international scientific 
practical conference (pp. 47-50). Moscow: Pudlishing house MGOU.

Castaneda, C. (1972). Journey to Ixtlan: The Lessons of Don Juan (p. 315). New York: Simon \& Schuster.

Castaneda, C. (1991a). Tales Of Power (p. 304). New York: Simon \& Schuster.

Castaneda, C. (1991b). The Fire from Within (p. 304). New York: Simon \& Schuster.

Castaneda, C. (1991c). The power of Silence (p. 288). New York: Simon \& Schuster.

Castaneda, C. (1993). The Art of Dreaming (p. 260). New York: Harper Collins Publishers.

Gelmgolts G. (1975). About a perception in general (pp. 61-87). The chrestomathy of a sensation and perception, under the edition of Gippenreiter Y.B. Moscow.

Gershenfeld, N. (1999). The Nature of Mathematical Modeling (p. 344). Cambridge University Press.

Magasov, S. S. (2007). Cognitive processes and models (p. 248). Moscow: The publishing house LKI.

Malinovsky, L. G. (2003). A model constructing thinking (p. 656). Moscow: Science.

Peter, S. (2006). The Fifth Discipline (p. 445). New York: Doubleday.

Rubin, M. S. (2003). The principles of the model thinking in TRIS (pp. 169-174). Scientific practical conference "The system of the teachers training, specialists and researchers TRIS". The thesis of the reports. Petrozavodsk.

St. Symeon the New Theologian. (1993). Creations book 2, words 53-92. Sergiev Posad: The Holy Trinity-St. Sergius Lavra (p. 593).

Thinking. Wikipedia. Retrieved January 27, 2014, from http://ru.wikipedia.org/wiki/Мышление_(философия)

\section{Copyrights}

Copyright for this article is retained by the author(s), with first publication rights granted to the journal.

This is an open-access article distributed under the terms and conditions of the Creative Commons Attribution license (http://creativecommons.org/licenses/by/3.0/). 